\title{
Resilience Improves Neurocognition and Treatment Outcomes in Schizophrenia: A Hypothesis
}

\author{
Amresh Shrivastava' ${ }^{1}$, Avinash De Sousa ${ }^{2 *}$, Sushma Sonavane ${ }^{2}$, Nilesh Shah ${ }^{2}$ \\ ${ }^{1}$ Department of Psychiatry, The Western University, Lawson Health Research Institute, London, Canada \\ ${ }^{2}$ Department of Psychiatry, Lokmanya Tilak Municipal Medical College, Mumbai, India \\ Email: "avinashdes888@gmail.com
}

Received 22 December 2015; accepted 3 April 2016; published 6 April 2016

Copyright (C) 2016 by author and Scientific Research Publishing Inc.

This work is licensed under the Creative Commons Attribution International License (CC BY). http://creativecommons.org/licenses/by/4.0/

(c) (†) Open Access

\begin{abstract}
There has been a revolutionary advance in the treatment and management of schizophrenia from a clinical aspect yet the social and functional outcomes remain poor. Cognitive function is impaired in schizophrenia and shows various domains of dysfunction like verbal memory, processing speed and working memory. It is also known to be a factor associated with poor outcome in schizophrenia. Resilience is a new concept psychobiological concept which is defined as individual's ability to adapt swiftly to adverse life events and bounces back to normalcy. Resilience has genetic, neurobiological, neurochemical and psychological underpinnings. It is the ability to effectively deal with psychosocial stressors and appears to be one of the many factors associated with favourable outcomes in schizophrenia. Besides several neurobiological abnormalities associated with resilience, neucognitive functions are of particular interest. Persistent psychosocial stressors also lead to significant neurobiological changes which may be synergetic to poor outcome due to cognitive changes. Though there has been extensive research in the field of cognitive function in schizophrenia, the trajectory of its pathway of poor outcome remains undetermined. Resilience being a protective factor may be one of the psychobiological functions which modulate the effect of neurocognition on the outcome of schizophrenia. There has been some success with interventions aimed at improving cognitive function in schizophrenia whether pharmacological or non pharmacological. In this paper, we discuss a hypothesis that resilience may be a "linkage" between cognition and outcome. There is a need for interventions aimed at increasing resilience in patients with schizophrenia and we hypothesize giving evidence that this may in turn improve outcome and neurocognitive functioning in schizophrenia.
\end{abstract}

\section{Keywords}

Resilience, Cognition, Neurocognition, Schizophrenia, Outcomes

\footnotetext{
${ }^{*}$ Corresponding author.

How to cite this paper: Shrivastava, A., De Sousa, A., Sonavane, S. and Shah, N. (2016) Resilience Improves Neurocognition and Treatment Outcomes in Schizophrenia: A Hypothesis. Open Journal of Psychiatry, 6, 173-187.
}

http://dx.doi.org/10.4236/ojpsych.2016.62021 


\section{Introduction}

Schizophrenia is a disorder both biological and neurocognitive in nature seen in about $0.6 \%$ to $1 \%$ of the population [1]. Though about one third of the patients are able to achieve satisfactory remission in clinical symptoms and an improved level of functioning, majority of them still live a difficult life with persisting symptoms and poor productivity [2]. The disease burden caused by schizophrenia is immense. Patients with schizophrenia have been reported to have higher rates of physical disorders than the general population and their average life span is shorter with about 5\% to $8 \%$ committing suicide in their lifetime [3] [4]. Neurocognitive abnormalities are the hallmark of schizophrenia and are responsible for the socio-occupational decline and interpersonal problems that may ensue as the disorder progresses [5]. There is strong scientific evidence that neurocognitive function (NCF) is one of most reliable predictors of outcome in schizophrenia and its impairment leads to poorer social and functional outcomes [6]. We have seen a revolutionary advance in the treatment of schizophrenia due to which patients now live in communities and are showing better rates of symptom remission than before [7]. However, schizophrenia still has a poor social and functional outcome, which disappoints many aspirations of patients and relatives to move towards a state of wellness from state of illness [8].

Only $30 \%$ to 50\% patients achieve social recovery. There are a number of factors responsible for such poor functional outcomes and the most important one is cognitive impairment, which is seen in almost all patients with the disorder. [9]. Cognitive impairment sets in early in the course of the illness being one of the most reliable predictors of the course and outcome of illness and remains resistant to any treatment [10]. There are neurobiological changes in the brain which significantly correlates with cognitive function and expected outcome status [11]. There has been significant research in the field of cognitive neuroscience and its nature, extent and severity are clearly understood in the case of schizophrenia [12]. Exhaustive research done in this area almost conclusively describes that neurocognitive abnormalities predates onset of symptoms in schizophrenia and is certainly related to outcome [13]. It has also been shown that psychosocial and environmental factors adversely affect outcome though while psychosocial treatments improve the outcome, there are no definite treatments which enhance cognition and hence outcomes in schizophrenia continue to suffer [14]. NCF is directly related to neurobiological, neural functioning and neuronal changes [15]. Despite this body of knowledge, there lack a clear trajectory of changes both biological and psychosocial that can explain how neurocognitive impairment leads to poorer outcome and whether improvement in NCF will be effective for better outcomes [16]. It is important to explore the association between cognition and schizophrenia and in particular to examine if cognition is a modifiable factor [17]. Due to a lack of knowledge about a pathway and how this relationship occurs, our focus of intervention to improve outcomes has been directed towards viz. (1) dealing with processes so that cognitive impairments do not increase and (2) decreasing consequences of cognitive impairment by targeting behavioral symptoms that illustrate it. There has been very limited success based upon this approach whether we use pharmacological, psychological or rehabilitation methods [18].

There are a number of processes which may affect neurobiological pathways from dysfunction to outcome and these maybe more intrinsic than extrinsic e.g. individual aspirations, ability to cope and self-awareness [19]. Studies have shown that resilience is a factor, which promotes positive psychology and improves individual sense of well being which may be a necessary component of social and functional outcomes [20]. Studies also suggest that besides several structural and functional changes in the brain, low level of resilience is associated with neurocognitive dysfunction [21]. Resilience is a psychobiological construct which determines the individual's response to adverse life events and promotes positive mental health-a state of well-being [22]. Resilient people have high ability to give a robust response to a stressful event and possess the capacity to feel satisfaction, contentment and optimism in life leading to an overall improved well-being, reduced negative consequences of adverse events, lesser impact of psychosocial stress, improved outcome of psychiatric disorders and enhanced neurocognition [23]. Resilience is also a protective factor against mental disorder and lack of resilience is a risk factor for the development of psychiatric disorders [24]. If this is true the probably resilience is a factor at least partly is responsible for the poor outcome caused due to neurocognitive impairment in psychiatric disorders. We believe that the mechanism by which cognitive impairment causes poor outcome may me mediated by resilience and thus patients with high resilience will have less severe consequences of cognitive impairment in any form of psychopathology. We also believe that higher resilience promotes robust response in face of severe psychosocial events, which is extremely common in disorders like schizophrenia throughout the course of the illness [25]. Good resilience may cause less cognitive dysfunction leading to better treatment outcomes by decreasing the in- 
dividual's response to psychosocial stress and we propose to hypothesize that resilience is a marker to improve neurocognition and outcome amongst patients suffering from schizophrenia.

In this paper, we will briefly describe current state of understanding of outcomes in schizophrenia, neurocognitive deficits seen and the concept of resilience in relations to the same. We shall also briefly discuss how improving resilience can improve outcomes of schizophrenia.

\subsection{Outcomes in Schizophrenia and Resilience}

In clinical practice, studies have demonstrated that $60 \%$ - 80\% patients with schizophrenia recover in 12 to 52 weeks, however, only $30 \%-40 \%$ achieve clinical as well as functional recovery [26]. In the long term follow up ( 5 - 10 years), the outcome does not increase beyond 30\%. It is a matter of concern that the relapse rate in first episode schizophrenia is more than $80 \%$ in first 5 years after the episode [27]. In our own previous study, in a 10 year follow-up of first episode schizophrenia, only $23 \%$ of patients showed both clinical and social recovery [27]. Without achieving social outcome, treatment success is incomplete. The concept of outcome in schizophrenia is continuously evolving and expectations have risen as more effective treatments are available [28]. Patients and relatives are aspiring to move towards a state of wellness from a state of illness [29]. Cognitive dysfunction sets in prior to appearance of any symptoms, is seen in most patients and remains quite resistant to treatment. It has a distinct neurobiology and cannot be reversed or minimized by any of the current available treatments [30]. Cognitive dysfunction leads to poor treatment outcome by decreasing the individual's response to psychosocial stressors that may arise, and this response is partially determined by resilience [31]. It is therefore likely that neurocognitive change could be one of the factors, which lead to poor outcomes. If this is the case, it explains how cognitive enhancement therapies (e.g. remediation, behavioral therapies and mindfulness) improve the outcomes of mental disorder [32]. Cognitive dysfunction is related to poor outcome on all parameters but it is more pronounced on social and functional outcomes [33]. Neurocognitive dysfunction in schizophrenia is generalized and correlates with functional changes and has its origin in neuronal development and poor neuronal architecture in schizophrenia [34]. It interferes with process of learning, memory social cognition and metacognition to finally lead to functional impairment and disability [35]. However a clear pathway of association between poor outcome and cognitive impairment is still undetermined. A number of neurobiological and psychobiological processes are involved to explain the mechanism of a pathway for poor outcomes from cognitive impairment. The four components interact viz. resilience, cognition, the schizophrenic process and severity of psychosocial stressors involved [36]. Further, methods, which can increase resilience, can also decrease the negative consequences of psychosocial stress, improve neurocognitive dysfunction and thereby improve outcomes of psychiatric disorders.

Despite the significant advances in treatment, outcomes of schizophrenia remain limited in both short term and well as in the long term course of the illness [37]. There are number of reasons for this starting with the fact that we do not have a correct definition of outcome as the concept of outcome has been evolving to enclose a number of themes which are arising from the expectations of patients, relatives, treating psychiatrists, health care agencies, policy makers and advocacy groups [38]. This limits our parameters of assessment. Meltzer defined 13 criteria for outcome in schizophrenia however it remained undetermined as to how many criteria were sufficient enough to describe a patient as having been recovered [39]. Patients recover differently on different parameters and the number of patients recovering on all possible parameters is extremely poor [40]. A minimum parameter of care usually accepted for standard of care remains clinical, social and functional. What causes a good outcome and how does one identify the candidates who may not recover is the key issue. How to treat in a manner to obtain good outcome and finally what should be the direction of newer research to maximise outcomes so that patients reach a state in which they can have total social integration in society [41]. Studies show that overall only about $40 \%$ patients recover in long term, $50 \%$ in medium term and $60 \%$ in short term outcome measures [42]. For various reasons, patients assessed as 'recovered' remain excluded from mainstream society. In one of our studies, we have argued that present outcome measures do not capture real-life situations. We propose that the concept of recovery be carefully defined and the gold standard of outcome should incorporate social and clinical parameters [43]. In a review of 50 studies, it was noted by researchers that the median proportion ( $25 \%$ - $75 \%$ percentile) who met our recovery criteria was $13.5 \%$ (8.1\% - 20.0\%). They concluded that based on the best available data, approximately, only 1 in 7 individuals with schizophrenia met their criteria for recovery [44]. Despite major changes in treatment options in the recent decades, the proportion of recovered 
cases has not increased [45]. Similarly in our long term 10 year follow up study 37\% patients did not have any improvement in interpersonal social functions while $56 \%$ patients were unable to live independently, $41 \%$ patients did not achieve satisfactory quality of life and only 58\% improved on levels of functioning. A decline of cognition was observed in $50.3 \%$ patients, which is universally acknowledged as responsible for lower level of functioning [27]. Other contributing factors appear to be lack of opportunity for employment and work, leading to lack of satisfaction, stigma and being seen as a burden on the family, at least in a few cases [46]. However persistence of symptoms, suicidality, limited functioning, inability for independent living, and inability to resume work in large number of patients does bring out limited success with contemporary therapy [47]. In another study which compared rates hospitalization between 1994 and 2004, authors highlighted admission rates of $50 \%$ and $85 \%$ on first generation antipsychotic drugs and 51 and $81 \%$ on second generation antipsychotic drugs respectively. 52\% patients were not able to go back to school/college or to productive employment [48]. Another long term study reports that almost half of participants were still living with their parents (48.1\%) or in assisted or semi-assisted living conditions (33.3\%) and only 18.5\% were working in the open market [49]. It has also been reported that rehabilitation in work is higher in short-term outcomes, however with repeated relapses and hospitalizations the decline is more severe [50].

\subsection{Resilience, Mental Health and Psychiatric Disorders}

Resilience is a fundamental psychological trait which determines the ability of an individual to adapt to adverse life events and cope with stressful situations [51]. Resilience leads to increase in the ability to adapt to adverse events, increased optimism, well-being, satisfaction, achievement, social engagement and contentment [52]. It plays an important role in maintaining psychological states which provide protection against adversities in both acute and chronic conditions, minimizing the extent of pathogenesis in the developmental process of transition from health to disease, facilitating return to the original state once the adverse situation has changed and it reduces an individual's vulnerability to psychiatric disorders [53]. Overall it leads to positive psychological health. Individuals having high resilience tend to have a purpose of life and experience positive emotions [54]. Resilience leads to improved recovery after experiencing adverse life events and now recovery from serious mental illness is understood more as personal growth and developing a meaningful life after the illness [55].

Fundamental questions arise in connection with resilience and its association with health and disease. Does it play a role in the process of pathogenesis of a psychiatric or physical disorder and if this is so, then how. The level of resilience has been identified as a protective factor to against developing a psychiatric disorder [56]. The ability to achieve the goals of recovery implies the presence of individual resilience [57]. Resilience is commonly conceptualized as the ability to adapt and thrive despite experiencing adversity. Resilience is a fairly new area of research in adult psychiatry and faces many hurdles towards investigation. The interest in studying resilience arises from a number of areas, such as exploring the possibility of at-risk individuals to developing a mental illness; or from a psychological point of view, in interest of nature's primal process of adaptation [58].

The level of resilience has been identified as a protective factor to lower the chances of developing a psychiatric disorder. The concept of resiliency can be applied to pathology-oriented treatment approaches for severe mental illness [59]. Resilience is an independent psychopathological construct and is involved in both health and disease. Thus it determines psychopathology, course, outcome, distress and burden of illness [60]. An individual's ability to deal with a stressful stimulus depends on five factors viz. personality, neurobiological factors, genetics, social determinants and resilience [61]. These are all independent of each other. Ideally, psychiatric treatment involves reduction of symptoms, recovery, and remission. Of late, treatment has been aspired to bring the patient back to his/her original state as before the illness, where resilience comes into play [62]. Research in the neurobiology of resilience can advance us in the knowledge of pin pointing where and what are the correlates of resilience [63]. For example, one of the basic principles in the concept is that adaptation in neural systems in response to stress causes deformation, and the ability to reset to an optimal state is resilience [64]. Major findings are available from the field of neurochemistry, functional brain changes, neuronal connectivity, neuroendocrinology and neurobiology with regards to the response to stress and adverse events [65]. The brain is constantly adapting to a changing environment. It detects environmental stimuli, integrates information with internal states and engages appropriate behavioural and physiological responses [66].

Acute stress response systems like the hypothalamo-pituitary-adrenal (HPA) axis and neurotransmitters such as norepinephrine (NE), serotonin (5-HT) and gluococorticoids (GC) are involved in the response to stress [67]. The HPA axis elicits release of cortisol which travels throughout the body inciting the physiological response 
required to cope with the stressor. A substantial body of literature exploring cortisol dysregulation in major depressive disorder and post-traumatic stress disorder (PTSD) has emerged in the past few decades [68]. Active coping and seeking social support have been described as resilient processes that facilitate resistance to or recovery from, trauma. Other processes shown to be adaptive in relation to stress and trauma include the capacity to generate positive emotions, to accept that which cannot be changed, and to reframe the negative into positive [69]. Clinical significance of research on resilience is around the area of prediction and prevention of mental disorders [70]. Both clinical and animal studies are trying to explore the possibility of identifying candidates who may develop depression, PTSD or schizophrenia if they have faced with adverse life situations [71]. Relationship of stressful life events and psychiatric disorders are under investigation to find out if an individual will develop an illness and if so what treatment can either prevent or treat the same [72]. Mostly, these clinical investigations are from the field of PTSD and depression research [73]. Another important area of investigation is ultrahigh risk (UHR) conditions for psychosis. Studies around UHR show that psychosocial functioning in UHR participants is often compromised; this dysfunction is often associated with negative symptoms, adaptive coping, and low resilience. Interestingly baseline resilience is found to be lower among those in the UHR group who converted to frank psychosis than among those who did not [74].

Though it is not clear whether resilience is a modifiable or non-modifiable factor, studies report that resilience is affected by pharmacological interventions like antidepressants [75]. Understanding the psychology and neurobiology underlying resilience will help develop strategies aimed at preventing psychopathology after exposure to severe adversity. However individual differences exist, which determine the nature of psychopathology, response to treatment and outcome [76]. Reasons for such differences are complex and have been hampering the efforts to obtain best possible quality of life despite similar treatments and treatment settings.

\subsection{Neurocognitive Function and Schizophrenia}

Cognitive functioning is affected (moderate to severe) in patients with schizophrenia [77]. This impairment is themain factor related to disabilities in occupational, social and economic functioning in patients with schizophrenia and is an important treatment target [78]. The profile of deficits in schizophrenia includes many of the most important aspects of human cognition like attention, memory, reasoning and processing speed [79]. While various efforts are under way to identify specific aspects of neurocognition that may lie closest to the neurobiological etiology and pathophysiology of schizophrenia, providing relevant convergence with animal models of cognition, standard neuropsychological measures continue to demonstrate the greatest sensitivity to functionally relevant cognitive impairment [80].

Kraepelin described the term "dementia praecox" which literally means cognitive decline with its onset in youth and this was reconfirmed by Blueler in 1911 [81]. The cognitive deficit is generalized in nature and is more pronounced in few localized areas. A review on the subject describes cognitive changes in a systematic manner [82]. They discussed the changes in memory, processing speed, verbal fluency, attention, executive function and working memory. Cognitive deficit predates the onset of symptoms. It persists through the longterm course of schizophrenia [83]. Modest improvements in cognitive function are observed in the course of antipsychotic treatment [84]. The course of cognitive function through schizophrenic illness has not been definitively outlined. Cognitive impairment, social cognition such as deficits in a theory of mind is a strong predictor of poor social and vocational outcome. Though cognitive deficits in patients with schizophrenia tend to be more severe and persistent compared to patients with psychotic and non-psychotic affective disorders, they are not qualitatively different [85]. The impairment may change in nature and degree but overall it is fairly stable throughout the entire course of schizophrenia except in early phase where it continues to decline [86]. Studies imply that it can distinguish patients with schizophrenia from normal controls with more specificity than imaging evidence or other techniques [87]. Cognition has been proposed as criteria to diagnose schizophrenia explaining its sensitivity and significance [88].

There has been considerable research understanding the mechanisms that generate cognitive dysfunction. Studies from genetics, neurochemistry and neuroimaging throw sufficient light on the subject though detailed elucidations are beyond the scope of this review [89]. There is a significant neuronal loss in overall growth of the brain and particularly in the localized areas of the prefrontal cortex and hippocampus [90] [91]. This neuronal loss and abnormal architecture of the neuronal mesh remains vulnerable due to deficiencies of protein substances like BDNF [92]. An aggregate brain lesion is reflected in functional as well as structural imaging. These 
neurobiological changes have reliable degree of correlation with cognitive impairment as measured by several neuropsychological tests; however it is important to remember that our methods of measurement of neuropsychological changes are not yet sophisticated enough and we know only what we can measure [93]. There are definite questions like whether we measuring the right cognitive function and whether we are measuring with sensitivity and specificity [94]. Abnormalities of neurotransmitter systems represent more central changes in several pathways like dopamine, GABA, NMDA and acetylcholine [95]. These neurotransmitters are under direct genetic control most prominently being the catechol-O-methyl transferase (COMT) gene [96].

The process and mechanism of how neurocognitive impairment leads to poor outcome on clinical, social and personal parameters, is not clearly known. Findings from psychological and neurobiological research do not provide a clear trajectory [97]. Most likely such mechanisms involve findings from the neurobehavioral, psychological and neurobiological fields while findings from research aboutthe resilient brain, social cognition, metacognition and cognitive resiliency are significant in explaining this complexity [98]. Cognitive testing indicates that dysfunction of the frontal lobes, temporal lobes, left or right hemispheres in general and their connections to the basal ganglia are involved though the causal directions of these associations have not been established [99]. About $80 \%$ of individuals with a diagnosis of schizophrenia struggle with a variety of neurocognitive and socio-cognitive deficits [100]. The neuro-cognitive domains typically affected include speed of processing, attention/vigilance, working memory, verbal learning, reasoning and problem solving [33] whereas social cue perception, affect recognition, attribution, and theory of mind are the socio-cognitive domains most affected [101]. How cognitive impairment leads to decreased social and functional capacity remains much more obscure and complex. Many attempts have been made to decode such behavioral responses, but with only little success.

It is presumed that some final common pathway exists which arises from an overlapping feature of psychological and neurobiological dimensions. A number of theories have been proposed. All the models and theories arise from the assumption that neurobiological changes take place much early in life [102]. The process of dysfunction is sufficient to cause learning and memory impairment and leads to poor capacity for behavioral responses [103]. The final common pathway appears to be a sequential change from neurocognitive dysfunction to social cognition which leads to meta-cognitive changes. This supports the idea of impaired social functioningregardless of whether it is social communication or performance. This may be attributed to impaired metacognitive or social cognitive abilities in patients with schizophrenia above and beyond neurocognitive impairments [104]. Here there may be a common mechanism suggesting impairment in working memory to guide behavior and a function we refer to as proactive control. There may be a theoretical link between cellular abnormalities (e.g., reductions in dendritic spines, and interneuron dysfunction), functional disturbances in local circuit function (e.g., gamma abnormalities), altered inter-regional cortical connectivity, a range of higher cognitive deficits, and symptom presentation (e.g., disorganization) in schizophrenia [105]. Another mechanism suggests that learning is based on repeating a task which becomes gradually more difficult [106]. Learning impairments have been consistently reported in schizophrenia while there is still a debate over impairments to implicit learning. For example, some studies report that implicit learning is intact for tasks such as probabilistic classification learning [107], weather prediction and artificial grammar learning [108], while others report an impairment in color pattern learning but not in letter string learning [109]. The impact of metacognition on awareness of illness and social functioning seems to be partially independent of neurocognitive functioning [110]. Research into metacognitive abilities in schizophrenia has revealed new insights into the understanding of individual symptoms and outcome measures, with potentially important implications for psychotherapy and meta-cognitive remediation in schizophrenia [111].

Several sub-processes may be involved in explaining such a link between poor understanding of mental states and impaired social or community functioning. This involves deficit in emotion regulation, enhanced cognitive biases, deficit in social communication skill and poor awareness of illness [112]. Metacognitive deficits seem to be most severe in patients with prominent disorganization symptoms [113]. Accordingly, it is equally unknown whether patients with different subtypes respond differentially to social cognitive remediation therapy [114]. A number of studies involving antipsychotic treatments, behavior therapy and rehabilitation are present. Trials of medication have met with little success, potentially requiring exploration of non-drug treatment [115]. Antipsychotic effects on cognition and pharmacological augmentation as a cognitive enhancement strategy have met with limited success. The effects of antipsychotic medications on cognition in schizophrenia and first-episode psychosis appear to be minimal [116]. Important work on the effects of add-on pharmacologic treatments is on- 
going. Very few of the studies completed to date have had sufficient statistical power to generate firm conclusions; recent studies examining novel add-on treatments have produced some encouraging findings [83] [117]. Cognitive remediation programs have generated considerable interest as these methods are far less costly than pharmacologic treatment and are likely to be safer [118]. A growing consensus suggests that these interventions produce modest gains for patients with schizophrenia, but the efficacy of the various methods used has not been empirically investigated. In neurocognition, drill and practice training is used more frequently and with a variety of different procedures such as auditory training or target discrimination [119]. Tailoring the training to specifically address precise deficits might be one of the key benefits of drill and practice training. However, from the studies we evaluated, drill and strategy training was more easily generalized to all neurocognitive deficits. Indeed, a recent meta-analysis on the benefits of cognitive remediation in schizophrenia noted that this modality of training produces stable benefits on global cognition [120].

Another approach for dealing with resistant cognitive function is to deal with the determinants of cognition. It is in this connection that research on resilience is significant which examines if personal factors can make any difference to cognition.

\subsection{Resilience and Neurocognition-The Relationship}

The main question in focus here is whether the trajectory of cognitive impairment is determined or defined by resilience and if so then what are the factors between the two? We also try to examine whether there is a clinical implication of this phenomenon. As stated above there are both direct as well as indirect evidence for the complex interaction between resilience and cognition. Resilience is a factor which determined a number of factors which are closely related to outcome in schizophrenia. Resilience is no doubt an outcome determinant in schizophrenia. Resilience as described earlier in this paper is a human capacity to adapt swiftly and successfully to a stressful or traumatic event and return back to a positive state. Recovery from serious mental illness is now understood as involving personal growth, expanding abilities, and developing a meaningful life despite illness [121]. The ability to achieve the goals of recovery implies the presence of individual resilience. If resilience is the ability to experience severely stressful events and not develop mental illness, then possibly, people who experience stressful events and develop schizophrenia are demonstrating vulnerability [122]. Resilient individuals have at their disposal, a number of supportive factors that are protective when risk or a significant threat is present [123]. The relationship of resilience-cognition and schizophrenia is too complex, while cognition forms only a part of the illness, resilience is involved in the entire process of development of the illness [124]. Resilience is associated with genetic vulnerability and evidence for this is arising from low levels of resilience noted in mothers of schizophrenic patients [125]. The increased vulnerability which gives rise to this is perceived as a threshold dispenses of the individual towards stimuli. Resilience requires more than a return to original functioning and expects that additional experiences will be gathered to underpin the ability to grow after recovering functioning [126]. The subject of cognitive neuroscience and resilience being responsible for outcome in schizophrenia is complex. Resilience is one of the recent areas of research in adult mental health. Number of studies shows its significance in determining general well being in patients suffering from mental disorder [127]. However, very little work is available in the field of cognitive dysfunction, resilience and schizophrenia. It is clear that neurocognitive impairment is one of the most important symptom, cluster or domain, which determines major share of functional outcome. Many studies have repeatedly demonstrated that it is resistant to treatment [128].

Studies also show that resilience is a protective factor against development of mental illness and has a neurobiological basis [129]. Available evidence suggests that poor outcome may be resulting from a shared and combined effect of neurocognitive impairment by schizophrenia psychopathology and resilience [130]. This intricate relationship involves a process, which relates to genetic vulnerability and thus functional outcome seems to be associated amongst others with less vulnerability and greater resilience [131]. Studies suggest that patients with lower level of resilience deal poorly with adverse situation and stressful conditions. Individuals with high resilience suffer from low psychopathology and recover better [132]. Resilience can also prevent progression of pathology thus it can improve function in both symptomatic and asymptomatic conditions. One of the pathways is direct impact of resilience on outcome because it enables patients to deal with stressful situations, be more satisfied and have more capacity to cope with the illness. Overall these patients achieve a better quality of life [133]. Yet another process involves neurobiological and neurocognitive pathways. In neurobiological pathways there appears to be shared abnormality between functional and anatomical changes caused by low level of resilience 
and neurocognition itself [134]. In recognition of the complexity of psychosocial dysfunction offers a starting point to systematically address the question of association of poor meta-cognition and symptomatology. This suggests that abilities to form representation of one's own mind are frequently disrupted which is the core symptom and part of the social problems found in psychosis [135].

The inability to initiate an action on the basis of one's own intentions may manifest in form of disorganised behaviour. With regard to social functioning there are a range of reasons to assume that hypothesized deficits in meta-cognition might impact social and vocational functions as well [136]. There is evidence of meta-cognitive deficits that might be expected to limit psychosocial functions. It is not clear though what deficits are related to which kind of function and exactly in which manner. More important is the question whether meta-cognitive function is linked to psychosocial function independent of neurocognitive impairment remains unclear [137].

\subsection{Certain Viewpoints}

Thus functional outcome seems to be associated to less vulnerability and greater resilience. In the pathway towards poor outcome two main processes take place viz. the mechanism of deficiencies in learning, which leads to neurobehavioral response and thereby leading to poor functioning. This process involves sequence of changes, of impairment of learning and memory, leading to impaired social cognition [138]. Studies suggest that patients with lower level of resilience deal poorly with adverse situation and stressful conditions. Individuals with high resilience suffer from low psychopathology and recover better. Resilience can also prevent progression of pathology thus it can improve function in both symptomatic and asymptomatic conditions. One of the pathways is direct impact of resilience on outcome because it enables patients to deal with stressful situations, be more satisfied and have more capacity to cope with the illness. Overall these patients achieve a better quality of life. In neurobiological pathway there appears to be shared abnormality between functional and anatomical changes caused by low level of resilience and neurocognition itself. There is significant neuronal loss in overall growth of brain, which is localized in prefrontal cortex and hippocampus. In recognition of the complexity of psychosocial dysfunction offers a starting point to systematically address the question of association of poor metacognition and symptomatology. This suggests that abilities to form representation of once own mind are frequently disrupted which is the core symptom and social problems found in psychosis [139].

\section{Conclusion}

Resilience may thus serve as an outcome determinant in neurocognitive pathways in schizophrenia as it promotes personal growth as well as cognitive survival. Today we are at an era in the management of schizophrenia where most conventional therapies cause a symptom remission but fail to bring about good social and cognitive outcomes. Resilience based interventions in schizophrenia may hold the key in promoting long term well being in recovery from schizophrenia. Cognitive remediation and cognitive enhancing therapies when combined with resilience enhancing interventions may hold the key to promote neurocognitive pathway preservation in schizophrenia. The next step in the management of schizophrenia may well involve the methods to build resilience and promote enhancement of resilience.

\section{References}

[1] Leifker, F.R., Bowie, C.R. and Harvey, P.D. (2009) Determinants of Everyday Outcomes in Schizophrenia: The Influences of Cognitive Impairment, Functional Capacity, and Symptoms. Schizophrenia Research, 115, 82-87. http://dx.doi.org/10.1016/j.schres.2009.09.004

[2] Green, M.F., Kern, R.S. and Heaton, R.K. (2004) Longitudinal Studies of Cognition and Functional Outcome in Schizophrenia: Implications for MATRICS. Schizophrenia Research, 72, 41-51. http://dx.doi.org/10.1016/j.schres.2004.09.009

[3] Leucht, S. and Lasser, R. (2006) The Concepts of Remission and Recovery in Schizophrenia. Pharmacopsychiatry, 39, 161-170. http://dx.doi.org/10.1055/s-2006-949513

[4] Tsang, H.W. and Chen, E.Y. (2007) Perceptions on Remission and Recovery in Schizophrenia. Psychopathology, 40, 469-475. http://dx.doi.org/10.1159/000108128

[5] Schaefer, J., Giangrande, E., Weinberger, D.R. and Dickinson, D. (2013) The Global Cognitive Impairment in Schizophrenia: Consistent over Decades and around the World. Schizophrenia Research, 150, 42-50. http://dx.doi.org/10.1016/j.schres.2013.07.009 
[6] Frith, C.D. (2015). The Cognitive Neuropsychology of Schizophrenia. Classic Edition, Psychology Press, UK.

[7] Liberman, R.P. and Kopelowicz, A. (2005) Recovery in Schizophrenia: A Concept in Search of Research. Psychiatric Services, 56, 735-742. http://dx.doi.org/10.1176/appi.ps.56.6.735

[8] Fett, A.K.J., Viechtbauer, W., Penn, D.L., van Os, J. and Krabbendam, L. (2011) The Relationship between Neurocognition and Social Cognition with Functional Outcomes in Schizophrenia: A Meta-Analysis. Neuroscience \& Biobehavioral Reviews, 35, 573-588. http://dx.doi.org/10.1016/j.neubiorev.2010.07.001

[9] Timofeeva, O.A. and Levin, E.D. (2011) Glutamate and Nicotinic Receptor Interactions in Working Memory: Importance for the Cognitive Impairment of Schizophrenia. Neuroscience, 195, 21-36. http://dx.doi.org/10.1016/j.neuroscience.2011.08.038

[10] Goff, D.C., Hill, M. and Barch, D. (2011) The Treatment of Cognitive Impairment in Schizophrenia. Pharmacology Biochemistry and Behavior, 99, 245-253. http://dx.doi.org/10.1016/j.pbb.2010.11.009

[11] Schmidt, S.J., Mueller, D.R. and Roder, V. (2011) Social Cognition as a Mediator Variable between Neurocognition and Functional Outcome in Schizophrenia: Empirical Review and New Results by Structural Equation Modeling. Schizophrenia Bulletin, 37, S41-S54. http://dx.doi.org/10.1093/schbul/sbr079

[12] Lysaker, P.H., Gumley, A., Luedtke, B., Buck, K.D., Ringer, J.M., Olesek, K. and Dimaggio, G. (2013). Social Cognition and Metacognition in Schizophrenia: Evidence of Their Independence and Linkage with Outcomes. Acta Psychiatrica Scandinavica, 127, 239-247. http://dx.doi.org/10.1111/acps.12012

[13] Kreyenbuhl, J., Buchanan, R.W., Dickerson, F.B. and Dixon, L.B. (2010) The Schizophrenia Patient Outcomes Research Team (PORT): Updated Treatment Recommendations 2009. Schizophrenia Bulletin, 36, 94-103. http://dx.doi.org/10.1093/schbul/sbp130

[14] Fanning, J.R., Bell, M.D. and Fiszdon, J.M. (2012). Is It Possible to Have Impaired Neurocognition But Good Social Cognition in Schizophrenia ? Schizophrenia Research, 135, 68-71. http://dx.doi.org/10.1016/j.schres.2011.12.009

[15] Mackowick, K.M., Barr, M.S., Wing, V.C., Rabin, R.A., Ouellet-Plamondon, C. and George, T.P. (2014) Neurocognitive Endophenotypes in Schizophrenia: Modulation by Nicotinic Receptor Systems. Progress in Neuro-Psychopharmacology and Biological Psychiatry, 52, 79-85. http://dx.doi.org/10.1016/j.pnpbp.2013.07.010

[16] Keshavan, M.S., Tandon, R., Boutros, N.N. and Nasrallah, H.A. (2008) Schizophrenia, “Just the Facts”: What We Know in 2008: Part 3: Neurobiology. Schizophrenia Research, 106, 89-107. http://dx.doi.org/10.1016/j.schres.2008.07.020

[17] Hoe, M., Nakagami, E., Green, M.F. and Brekke, J.S. (2012) The Causal Relationships between Neurocognition, Social Cognition and Functional Outcome over Time in Schizophrenia: A Latent Difference Score Approach. Psychological Medicine, 42, 2287-2299. http://dx.doi.org/10.1017/S0033291712000578

[18] Ventura, J., Subotnik, K.L., Ered, A., Gretchen-Doorly, D., Hellemann, G.S., Vaskinn, A. and Nuechterlein, K.H. (2014) The Relationship of Attitudinal Beliefs to Negative Symptoms, Neurocognition, and Daily Functioning in Recent-Onset Schizophrenia. Schizophrenia Bulletin, 40, 1308-1318. http://dx.doi.org/10.1093/schbul/sbu002

[19] Désaméricq, G., Schurhoff, F., Meary, A., Szöke, A., Macquin-Mavier, I., Bachoud-Lévi, A.C. and Maison, P. (2014) Long-Term Neurocognitive Effects of Antipsychotics in Schizophrenia: A Network Meta-Analysis. European Journal of Clinical Pharmacology, 70, 127-134. http://dx.doi.org/10.1007/s00228-013-1600-y

[20] Cicchetti, D. (2010) Resilience under Conditions of Extreme Stress: A Multilevel Perspective. World Psychiatry 9, 145-154. http://dx.doi.org/10.1002/j.2051-5545.2010.tb00297.x

[21] Simeon, D., Yehuda, R., Cunill, R., Knutelska, M., Putnam F.W. and Smith, L.M. (2007) Factors Associated with Resilience in Healthy Adults. Psychoneuroendocrinology, 32, 1149-1152. http://dx.doi.org/10.1016/j.psyneuen.2007.08.005

[22] Sapienza, J.K. and Masten, A.S. (2011) Understanding and Promoting Resilience in Children and Youth. Current Opinion in Psychiatry, 24, 267-273. http://dx.doi.org/10.1097/YCO.0b013e32834776a8

[23] Ozbay, F., Fitterling, H., Charney, D. and Southwick, S. (2008) Social Support and Resilience to Stress across the Life Span: A Neurobiologic Framework. Current Psychiatry Reports, 10, 304-310. http://dx.doi.org/10.1007/s11920-008-0049-7

[24] Norris, F.H., Tracy, M. and Galea, S. (2009) Looking for Resilience: Understanding the Longitudinal Trajectories of Responses to Stress. Social Science and Medicine, 68, 2190-2198. http://dx.doi.org/10.1016/j.socscimed.2009.03.043

[25] Davydov, D.M., Stewart, R., Ritchie, K. and Chaudieu, I. (2010) Resilience and Mental Health. Clinical Psychology Review, 30, 479-495. http://dx.doi.org/10.1016/j.cpr.2010.03.003

[26] McCabe, R., Saidi, M. and Priebe, S. (2007) Patient-Reported Outcomes in Schizophrenia. British Journal of Psychiatry, 191, S21-S28. http://dx.doi.org/10.1192/bjp.191.50.s21

[27] Shrivastava, A., Shah, N., Johnston, M., Stitt, L. and Thakar, M. (2010) Predictors of Long-Term Outcome of First- 
Episode Schizophrenia: A Ten-Year Follow-Up Study. Indian Journal of Psychiatry, 52, 320-325. http://dx.doi.org/10.4103/0019-5545.74306

[28] Shrivastava, A., Johnston, M., Shah, N. and Bureau, Y. (2010) Redefining Outcome Measures in Schizophrenia: Integrating Social and Clinical Parameters. Current Opinion in Psychiatry, 23, 120-126. http://dx.doi.org/10.1097/YCO.0b013e328336662e

[29] Priebe, S. (2007) Social Outcomes in Schizophrenia. British Journal of Psychiatry, 191, S15-S20. http://dx.doi.org/10.1192/bjp.191.50.s15

[30] Ranganath, C., Minzenberg, M.J. and Ragland, J.D. (2008) The Cognitive Neuroscience of Memory Function and Dysfunction in Schizophrenia. Biological Psychiatry, 64, 18-25. http://dx.doi.org/10.1016/j.biopsych.2008.04.011

[31] Carter, C.S. and Barch, D.M. (2007) Cognitive Neuroscience-Based Approaches to Measuring and Improving Treatment Effects on Cognition in Schizophrenia: The CNTRICS Initiative. Schizophrenia Bulletin, 33, 1131-1137. http://dx.doi.org/10.1093/schbul/sbm081

[32] Dickinson, D., Ragland, J.D., Gold, J.M. and Gur, R.C. (2008) General and Specific Cognitive Deficits in Schizophrenia: Goliath Defeats DAVID? Biological Psychiatry, 64, 823-827. http://dx.doi.org/10.1016/j.biopsych.2008.04.005

[33] Penn, D.L., Sanna, L.J. and Roberts, D.L. (2008) Social Cognition in Schizophrenia: An Overview. Schizophrenia Bulletin, 34, 408-411. http://dx.doi.org/10.1093/schbul/sbn014

[34] Keefe, R.S., Bilder, R.M., Davis, S.M., Harvey, P.D., Palmer, B.W., Gold, J.M. and Lieberman, J.A. (2007) Neurocognitive Effects of Antipsychotic Medications in Patients with Chronic Schizophrenia in the CATIE Trial. Archives of General Psychiatry, 64, 633-647. http://dx.doi.org/10.1001/archpsyc.64.6.633

[35] Bliksted, V., Fagerlund, B., Weed, E., Frith, C. and Videbech, P. (2014) Social Cognition and Neurocognitive Deficits in First-Episode Schizophrenia. Schizophrenia Research, 153, 9-17. http://dx.doi.org/10.1016/j.schres.2014.01.010

[36] Schooler, N.R. (2006) Relapse Prevention and Recovery in the Treatment of Schizophrenia. Journal of Clinical Psychiatry, 67, 19-23.

[37] Frese, F.J., Knight, E.L. and Saks, E. (2009) Recovery from Schizophrenia: With Views of Psychiatrists, Psychologists and Others Diagnosed With this Disorder. Schizophrenia Bulletin, 35, 300-306. http://dx.doi.org/10.1093/schbul/sbn175

[38] Warner, R. (2009) Recovery from Schizophrenia and the Recovery Model. Current Opinion in Psychiatry, 22, 374-380. http://dx.doi.org/10.1097/YCO.0b013e32832c920b

[39] Altamura, A.C., Bobo, W.V. and Meltzer, H.Y. (2007) Factors Affecting Outcome in Schizophrenia and Their Relevance for Psychopharmacological Treatment. International Clinical Psychopharmacology, 22, 249-267. http://dx.doi.org/10.1097/YIC.0b013e3280de2c7f

[40] Wunderlink, L., Sytema, S., Nienhuis, F.J. and Wiersma, D. (2009) Clinical Recovery in First Episode Psychosis. Schizophrenia Bulletin, 35, 362-369. http://dx.doi.org/10.1093/schbul/sbn143

[41] Yanos, P.T., Roe, D., Markus, K. and Lysaker, P.H. (2008) Pathways between Internalized Stigma and Outcomes Related to Recovery in Schizophrenia Spectrum Disorders. Psychiatric Services, 59, 1437-1442. http://dx.doi.org/10.1176/ps.2008.59.12.1437

[42] Vauth, R., Kleim, B., Wirtz, M. and Corrigan, P.W. (2007) Self-Efficacy and Empowerment as Outcomes of SelfStigmatizing and Coping in Schizophrenia. Psychiatric Research, 150, 71-80. http://dx.doi.org/10.1016/j.psychres.2006.07.005

[43] Llorca, P.M. (2008) Partial Compliance in Schizophrenia and the Impact on Patient Outcomes. Psychiatric Research, 161, 235-247. http://dx.doi.org/10.1016/j.psychres.2007.07.012

[44] Novick, D., Haro, J.M., Suarez, D., Vieta, E. and Naber, D. (2009) Recovery in the Outpatient Setting: 36-Month Results from the Schizophrenia Outpatients Health Outcomes (SOHO) Study. Schizophrenia Research, 108, 223-230. http://dx.doi.org/10.1016/j.schres.2008.11.007

[45] Kooyman, I., Dean, K., Harvey, S. and Walsh, E. (2007) Outcomes of Public Concern in Schizophrenia. British Journal of Psychiatry, 191, S29-S36. http://dx.doi.org/10.1192/bjp.191.50.s29

[46] Kim, E., Gupta, S., Bolge, S., Chen, C.C., Whitehead, R. and Bates, J.A. (2010) Adherence and Outcomes Associated with Copayment Burden in Schizophrenia: A Cross-Sectional Survey. Journal of Medical Economics, 13, 185-192. http://dx.doi.org/10.3111/13696991003723023

[47] Nielsen, J., Le Quach, P., Emborg, C., Foldager, L. and Correll, C.U. (2010) 10-Year Trends in the Treatment and Outcomes of Patients with First-Episode Schizophrenia. c, 122, 356-366. http://dx.doi.org/10.1111/j.1600-0447.2010.01576.x

[48] Sun, S.X., Liu, G.G., Christensen, D.B. and Fu, A.Z. (2007) Review and Analysis of Hospitalization Costs Associated with Antipsychotic Nonadherence in the Treatment of Schizophrenia in the United States. Current Medical Research 
Opinion, 23, 2305-2312. http://dx.doi.org/10.1185/030079907X226050

[49] Lambert, M., Naber, D., Schacht, A., Wagner, T., Hundemer, H.P., Karow, A. and Schimmelmann, B.G. (2008) Rates and Predictors of Remission and Recovery during 3 Years in 392 Never-Treated Patients with Schizophrenia. Acta Psychiatrica Scandinavica, 118, 220-229. http://dx.doi.org/10.1111/j.1600-0447.2008.01213.x

[50] Silverstein, S.M. and Bellack, A.S. (2008) A Scientific Agenda for the Concept of Recovery as It Applies to Schizophrenia. Clinical Psychology Review, 28, 1108-1124. http://dx.doi.org/10.1016/j.cpr.2008.03.004

[51] Dudley, K.J., Li, X., Kobor, M.S., Kippin, T.E. and Bredy, T.W. (2011) Epigenetic Mechanisms Mediating Vulnerability and Resilience to Psychiatric Disorders. Neuroscience \& Biobehavioral Reviews, 35, 1544-1551. http://dx.doi.org/10.1016/j.neubiorev.2010.12.016

[52] Collishaw, S., Pickles, A., Messer, J., Rutter, M., Shearer, C. and Maughan, B. (2007) Resilience to Adult Psychopathology Following Childhood Maltreatment: Evidence from a Community Sample. Child Abuse and Neglect, 31, 211229. http://dx.doi.org/10.1016/j.chiabu.2007.02.004

[53] Hoge, E.A., Austin, E.D. and Pollack, M.H. (2007) Resilience: Research Evidence and Conceptual Considerations for Posttraumatic Stress Disorder. Depression and Anxiety, 24, 139-152. http://dx.doi.org/10.1002/da.20175

[54] Rutter, M. (2007) Resilience, Competence, and Coping. Child Abuse and Neglect, 31, 205-209. http://dx.doi.org/10.1016/j.chiabu.2007.02.001

[55] Karatsoreos, I.N. and McEwen, B.S. (2011) Psychobiological Allostasis: Resistance, Resilience and Vulnerability. Trends in Cognitive Science, 15, 576-584. http://dx.doi.org/10.1016/j.tics.2011.10.005

[56] Earvolino-Ramirez, M. (2007) Resilience: A Concept Analysis. Nursing Forum, 42, 73-82. http://dx.doi.org/10.1111/j.1744-6198.2007.00070.x

[57] Goldstein, S. and Brooks, R.B. (2012) Handbook of Resilience in Children. Springer Science \& Business Media, Berlin.

[58] Insel, T.R. (2010) Rethinking Schizophrenia. Nature, 468, 187-193. http://dx.doi.org/10.1038/nature09552

[59] Lieberman, J.A., Perkins, D.O. and Jarskog, L.F. (2007) Neuroprotection: A Therapeutic Strategy to Prevent Deterioration Associated with Schizophrenia. CNS Spectrums, 12, 1-13.

[60] Zauszniewski, J.A., Bekhet, A.K. and Suresky, M.J. (2010) Resilience in Family Members of Persons with Serious Mental Illness. Nursing Clinics of North America, 45, 613-626. http://dx.doi.org/10.1016/j.cnur.2010.06.007

[61] Russo, S.J., Murrough, J.W., Han, M.H., Charney, D.S. and Nestler, E.J. (2012) Neurobiology of Resilience. Nature Neuroscience, 15, 1475-1484. http://dx.doi.org/10.1038/nn.3234

[62] Krystal, J.H. and Neumeister, A. (2009) Noradrenergic and Serotonergic Mechanisms in the Neurobiology of Posttraumatic Stress Disorder and Resilience. Brain Research, 1293, 12-23. http://dx.doi.org/10.1016/j.brainres.2009.03.044

[63] Karatoreos, I.N. and McEwen, B.S. (2013) Annual Research Review: The Neurobiology and Physiology of Resilience and Adaptation across the Life Course. Journal of Child Psychology and Psychiatry, 54, 337-347. http://dx.doi.org/10.1111/jcpp.12054

[64] Haglund, M.E., Nestadt, P.S., Cooper, N.S., Southwick, S.M. and Charney, D.S. (2007) Psychobiological Mechanisms of Resilience: Relevance to Prevention and Treatment of Stress-Related Psychopathology. Developmental Psychopathology, 19, 889-920. http://dx.doi.org/10.1017/S0954579407000430

[65] Fleshner, M., Maier, S.F., Lyons, D.M. and Raskind, M.A. (2011) The Neurobiology of the Stress-Resistant Brain. Stress, 14, 498-502. http://dx.doi.org/10.3109/10253890.2011.596865

[66] McEwen, B.S. (2007) Physiology and Neurobiology of Stress and Adaptation: Central Role of the Brain. Physiology Review, 87, 873-904. http://dx.doi.org/10.1152/physrev.00041.2006

[67] Gunnar, M. and Quevedo, K. (2007) The Neurobiology of Stress and Development. Annual Review of Psychology, 58, 145-173. http://dx.doi.org/10.1146/annurev.psych.58.110405.085605

[68] Weiss, S.J. (2007) Neurobiological Alterations Associated with Traumatic Stress. Perspectives in Psychiatric Care, 43, 114-122. http://dx.doi.org/10.1111/j.1744-6163.2007.00120.x

[69] Folkman, S. (2008) The Case for Positive Emotions in the Stress Process. Anxiety Stress and Coping, 21, 3-14. http://dx.doi.org/10.1080/10615800701740457

[70] Bhui, K. and Dinos, S. (2011) Preventive Psychiatry: A Paradigm to Improve Population Mental Health and Well-Being. British Journal of Psychiatry, 198, 417-419. http://dx.doi.org/10.1192/bjp.bp.110.091181

[71] Nestler, E.J. and Hyman, S.E. (2010) Animal Models of Neuropsychiatric Disorders. Nature Neuroscience, 13, 11611169. http://dx.doi.org/10.1038/nn.2647

[72] Keller, M.C., Neale, M.C. and Kendler, K.S. (2007) Association of Different Adverse Life Events with Distinct Pat- 
terns of Depressive Symptoms. American Journal of Psychiatry, 164, 1521-1529.

http://dx.doi.org/10.1176/appi.ajp.2007.06091564

[73] Brailey, K., Vasterling, J.J., Proctor, S.P., Constans, J.I. and Friedman, M.J. (2007) PTSD Symptoms, Life Events, and Unit Cohesion in US Soldiers: Baseline Findings from the Neurocognition Deployment Health Study. Journal of Trauma and Stress, 20, 495-503. http://dx.doi.org/10.1002/jts.20234

[74] Preti, A. and Cella, M. (2010) Randomized-Controlled Trials in People at Ultra High Risk of Psychosis: A Review of Treatment Effectiveness. Schizophrenia Research, 123, 30-36. http://dx.doi.org/10.1016/j.schres.2010.07.026

[75] Binder, E., Malki, K., Paya-Cano, J.L., Fernandes, C., Aitchison, K.J., Mathe, A.A., and Schalkwyk, L.C. (2011) Antidepressants and the Resilience to Early-Life Stress in Inbred Mouse Strains. Pharmacogenomics, 21, 779-789.

[76] Emsley, R., Chiliza, B. and Schoeman, R. (2008) Predictors of Long-Term Outcome in Schizophrenia. Current Opinion in Psychiatry, 21, 173-177. http://dx.doi.org/10.1097/YCO.0b013e3282f33f76

[77] Buchanan, R.W., Freedman, R., Javitt, D.C., Abi-Dargham, A. and Lieberman, J.A. (2007) Recent Advances in the Development of Novel Pharmacological Agents for the Treatment of Cognitive Impairments in Schizophrenia. Schizophrenia Bulletin, 33, 1120-1130. http://dx.doi.org/10.1093/schbul/sbm083

[78] McGurk, S.R., Twamley, E.W., Sitzer, D.I., McHugo, G.J. and Mueser, K.T. (2007) A Meta-Analysis of Cognitive Remediation in Schizophrenia. American Journal of Psychiatry, 164, 1791-1802. http://dx.doi.org/10.1176/appi.ajp.2007.07060906

[79] Frith, C.D. (2014) The Cognitive Neuropsychology of Schizophrenia. Psychology Press, UK.

[80] Keefe, R.S. and Fenton, W.S. (2007) How Should DSM-V Criteria for Schizophrenia Include Cognitive Impairment? Schizophrenia Bulletin, 33, 912-920. http://dx.doi.org/10.1093/schbul/sbm046

[81] Moskowitz, A. and Heim, G. (2011) Eugen Bleuler’s Dementia Praecox or the Group of Schizophrenias (1911): A Centenary Appreciation and Reconsideration. Schizophrenia Bulletin, 37, 471-479. http://dx.doi.org/10.1093/schbul/sbr016

[82] Tandon, R., Nasrallah, H.A. and Keshavan, M.S. (2009) Schizophrenia, “Just the Facts” 4. Clinical Features and Conceptualization. Schizophrenia Research, 110, 1-23. http://dx.doi.org/10.1016/j.schres.2009.03.005

[83] Combs, D.R., Adams, S.D., Penn, D.L., Roberts, D., Tiegreen, J. and Stem, P. (2007) Social Cognition and Interaction Training (SCIT) for Inpatients with Schizophrenia Spectrum Disorders: Preliminary Findings. Schizophrenia Research, 91, 112-116. http://dx.doi.org/10.1016/j.schres.2006.12.010

[84] Bora, E., Yucel, M. and Pantelis, C. (2009) Theory of Mind Impairment in Schizophrenia: Meta-Analysis. Schizophrenia Research, 109, 1-9. http://dx.doi.org/10.1016/j.schres.2008.12.020

[85] Barch, D.M. and Ceaser, A. (2012) Cognition in Schizophrenia: Core Psychological and Neural Mechanisms. Trends in Cognitive Science, 16, 27-34. http://dx.doi.org/10.1016/j.tics.2011.11.015

[86] Grant, P.M. and Beck, A.T. (2009) Defeatist Beliefs as a Mediator of Cognitive Impairment, Negative Symptoms, and Functioning in Schizophrenia. Schizophrenia Bulletin, 35, 798-806. http://dx.doi.org/10.1093/schbul/sbn008

[87] Keefe, R.S. (2008) Should Cognitive Impairment Be Included in the Diagnostic Criteria for Schizophrenia? World Psychiatry, 7, 22-28. http://dx.doi.org/10.1002/j.2051-5545.2008.tb00142.x

[88] Bowie, C.R. and Harvey, P.D. (2007) Predicting Real World Outcomes from Discrete Functional and Cognitive Abilities. Schizophrenia Bulletin, 33, 554.

[89] Lewis, D.A., Curley, A.A., Glausier, J.R. and Volk, D.W. (2012) Cortical Parvalbumin Interneurons and Cognitive Dysfunction in Schizophrenia. Trends in Neuroscience, 35, 57-67. http://dx.doi.org/10.1016/j.tins.2011.10.004

[90] Durstewitz, D. and Seamans, J.K. (2008) The Dual-State Theory of Prefrontal Cortex Dopamine Function with Relevance to Catechol-O-Methyltransferase Genotypes and Schizophrenia. Biological Psychiatry, 64, 739-749. http://dx.doi.org/10.1016/j.biopsych.2008.05.015

[91] Zhou, Y., Shu, N., Liu, Y., Song, M., Hao, Y., Liu, H. and Jiang, T. (2008) Altered Resting-State Functional Connectivity and Anatomical Connectivity of Hippocampus in Schizophrenia. Schizophrenia Research, 100, 120-132. http://dx.doi.org/10.1016/j.schres.2007.11.039

[92] Favalli, G., Li, J., Belmonte-de-Abreu, P., Wong, A.H. and Daskalakis, Z.J. (2012) The Role of BDNF in the Pathophysiology and Treatment of Schizophrenia. Journal of Psychiatric Research, 46, 1-11. http://dx.doi.org/10.1016/j.jpsychires.2011.09.022

[93] Bowie, C.R., Leung, W.W., Reichenberg, A., McClure, M.M., Patterson, T.L., Heaton, R.K. and Harvey, P.D. (2008) Predicting Schizophrenia Patients' Real-World Behavior with Specific Neuropsychological and Functional Capacity Measures. Biological Psychiatry, 63, 505-511. http://dx.doi.org/10.1016/j.biopsych.2007.05.022

[94] Reichenberg, A. and Harvey, P.D. (2007) Neuropsychological Impairments in Schizophrenia: Integration of Performance-Based and Brain Imaging Findings. Psychological Bulletin, 133, 833-838. 
http://dx.doi.org/10.1037/0033-2909.133.5.833

[95] Mesholam-Gately, R.I., Giuliano, A.J., Goff, K.P., Faraone, S.V. and Seidman, L.J. (2009) Neurocognition in First-Episode Schizophrenia: A Meta-Analytic Review. Neuropsychology, 23, 315-330. http://dx.doi.org/10.1037/a0014708

[96] Williams, H.J., Owen, M.J. and O’Donovan, M.C. (2007) Is COMT a Susceptibility Gene for Schizophrenia? Schizophrenia Bulletin, 33, 635-641. http://dx.doi.org/10.1093/schbul/sbm019

[97] Levine, S.Z., Lurie, I., Kohn, R. and Levav, I. (2011) Trajectories of the Course of Schizophrenia: From Progressive Deterioration to Amelioration over Three Decades. Schizophrenia Research, 126, 184-191. http://dx.doi.org/10.1016/j.schres.2010.10.026

[98] Moritz, S. and Woodward, T.S. (2007) Metacognitive Training in Schizophrenia: From Basic Research to Knowledge Translation and Intervention. Current Opinion in Psychiatry, 20, 619-625. http://dx.doi.org/10.1097/YCO.0b013e3282f0b8ed

[99] Lysaker, P.H., Dimaggio, G., Buck, K.D., Carcione, A. and Nicolò, G. (2007) Metacognition within Narratives of Schizophrenia: Associations with Multiple Domains of Neurocognition. Schizophrenia Research, 93, 278-287. http://dx.doi.org/10.1016/j.schres.2007.02.016

[100] Moritz, S., Vitzthum, F., Randjbar, S., Veckenstedt, R. and Woodward, T.S. (2010) Detecting and Defusing Cognitive Traps: Metacognitive Intervention in Schizophrenia. Current Opinion in Psychiatry, 23, 561-569. http://dx.doi.org/10.1097/YCO.0b013e32833d16a8

[101] Green, M.F., Penn, D.L., Bentall, R., Carpenter, W.T., Gaebel, W., Gur, R.C. and Heinssen, R. (2008) Social Cognition in Schizophrenia: An NIMH Workshop on Definitions, Assessment, and Research Opportunities. Schizophrenia Bulletin, 34, 1211-1220. http://dx.doi.org/10.1093/schbul/sbm145

[102] Rapoport, J.L., Giedd, J.N. and Gogtay, N. (2012) Neurodevelopmental Model of Schizophrenia: Update 2012. Molecular Psychiatry, 17, 1228-1238. http://dx.doi.org/10.1038/mp.2012.23

[103] El-Ghundi, M., O’Dowd, B.F. and George, S.R. (2007) Insights into the Role of Dopamine Receptor Systems in Learning and Memory. Reviews in Neuroscience, 18, 37-66. http://dx.doi.org/10.1515/revneuro.2007.18.1.37

[104] Lysaker, P.H., Warman, D.M., Dimaggio, G., Procacci, M., LaRocco, V.A., Clark, L.K. and Nicolò, G. (2008) Metacognition in Schizophrenia: Associations with Multiple Assessments of Executive Function. Journal of Nervous and Mental Disease, 196, 384-389. http://dx.doi.org/10.1097/NMD.0b013e3181710916

[105] Uhlhaas, P.J. and Singer, W. (2010) Abnormal Neural Oscillations and Synchrony in Schizophrenia. Nature Reviews Neuroscience, 11, 100-113. http://dx.doi.org/10.1038/nrn2774

[106] Farkas, M., Polgár, P., Kelemen, O., Réthelyi, J., Ritter, I., Myers, C.E. and Kéri, S. (2008) Associative Learning in Deficit and Non-Deficit Schizophrenia. NeuroReport, 19, 55-58. http://dx.doi.org/10.1097/WNR.0b013e3282f2dff6

[107] Strauss, G.P., Frank, M.J., Waltz, J.A., Kasanova, Z., Herbener, E.S. and Gold, J.M. (2011) Deficits in Positive Reinforcement Learning and Uncertainty-Driven Exploration Are Associated with Distinct Aspects of Negative Symptoms in Schizophrenia. Biological Psychiatry, 69, 424-431. http://dx.doi.org/10.1016/j.biopsych.2010.10.015

[108] Horan, W.P., Green, M.F., Knowlton, B.J., Wynn, J.K., Mintz, J. and Nuechterlein, K.H. (2008) Impaired Implicit Learning in Schizophrenia. Neuropsychology, 22, 606-610. http://dx.doi.org/10.1037/a0012602

[109] Choi, J. and Medalia, A. (2010) Intrinsic Motivation and Learning in a Schizophrenia Spectrum Sample. Schizophrenia Research, 118, 12-19. http://dx.doi.org/10.1016/j.schres.2009.08.001

[110] Aghotor, J., Pfueller, U., Moritz, S., Weisbrod, M. and Roesch-Ely, D. (2010) Metacognitive Training for Patients with Schizophrenia (MCT): Feasibility and Preliminary Evidence for Its Efficacy. Journal of Behaviour Therapy and Experimental Psychiatry, 41, 207-211. http://dx.doi.org/10.1016/j.jbtep.2010.01.004

[111] Moritz, S., Kerstan, A., Veckenstedt, R., Randjbar, S., Vitzthum, F., Schmidt, C. and Woodward, T.S. (2011) Further Evidence for the Efficacy of a Metacognitive Group Training in Schizophrenia. Behaviour Research and Therapy, 49, 151-157. http://dx.doi.org/10.1016/j.brat.2010.11.010

[112] Lysaker, P.H., Shea, A.M., Buck, K.D., Dimaggio, G., Nicolò, G., Procacci, M., Salvatore, G. and Rand, K.L. (2010) Metacognition as a Mediator of the Effects of Impairments in Neurocognition on Social Function in Schizophrenia Spectrum Disorders. Acta Psychiatrica Scandinavica, 122, 405-413.

[113] Lysaker, P.H., Buck, K.D. and Ringer, J. (2007) The Recovery of Metacognitive Capacity in Schizophrenia across 32 Months of Individual Psychotherapy: A Case Study. Psychotherapy Research, 17, 713-720. http://dx.doi.org/10.1080/10503300701255932

[114] Wykes, T., Reeder, C., Landau, S., Everitt, B., Knapp, M., Patel, A. and Romeo, R. (2007) Cognitive Remediation Therapy in Schizophrenia: Randomised Controlled Trial. British Journal of Psychiatry, 190, 421-427. http://dx.doi.org/10.1192/bjp.bp.106.026575 
[115] Medalia, A. and Choi, J. (2009) Cognitive Remediation in Schizophrenia. Neuropsychology Review, 19, 353-364. http://dx.doi.org/10.1007/s11065-009-9097-y

[116] Kurtz, M.M., Seltzer, J.C., Fujimoto, M., Shagan, D.S. and Wexler, B.E. (2009) Predictors of Change in Life Skills in Schizophrenia after Cognitive Remediation. Schizophrenia Research, 107, 267-274. http://dx.doi.org/10.1016/j.schres.2008.10.014

[117] Gray, J.A. and Roth, B.L. (2007) Molecular Targets for Treating Cognitive Dysfunction in Schizophrenia. Schizophrenia Bulletin, 33, 1100-1119. http://dx.doi.org/10.1093/schbul/sbm074

[118] Szöke, A., Trandafir, A., Dupont, M.E., Méary, A., Schürhoff, F. and Leboyer, M. (2008) Longitudinal Studies of Cognition in Schizophrenia: Meta-Analysis. British Journal of Psychiatry, 192, 248-257. http://dx.doi.org/10.1192/bjp.bp.106.029009

[119] Greig, T.C., Zito, W., Wexler, B.E., Fiszdon, J. and Bell, M.D. (2007) Improved Cognitive Function in Schizophrenia after One Year of Cognitive Training and Vocational Services. Schizophrenia Research, 96, 156-161. http://dx.doi.org/10.1016/j.schres.2007.07.003

[120] Wykes, T. and Huddy, V. (2009) Cognitive Remediation for Schizophrenia: It Is Even More Complicated. Current Opinion in Psychiatry, 22, 161-167. http://dx.doi.org/10.1097/YCO.0b013e328322fbf4

[121] Torgalsbøen, A.K. and Rund, B.R. (2010) Maintenance of Recovery from Schizophrenia at 20-Year Follow-Up: What Happened? Psychiatry, 73, 70-83. http://dx.doi.org/10.1521/psyc.2010.73.1.70

[122] Torgalsbøen, A.K. (2012) Sustaining Full Recovery in Schizophrenia after 15 Years: Does Resilience Matter? Clinical Schizophrenia and Related Psychoses, 5, 193-200. http://dx.doi.org/10.3371/CSRP.5.4.3

[123] Johnson, J., Gooding, P.A., Wood, A.M., Taylor, P.J., Pratt, D. and Tarrier, N. (2010) Resilience to Suicidal Ideation in Psychosis: Positive Self-Appraisals Buffer the Impact of Hopelessness. Behaviour Research and Therapy, 48, 883-889. http://dx.doi.org/10.1016/j.brat.2010.05.013

[124] Coifman, K.G., Bonanno, G.A., Ray, R.D. and Gross, J.J. (2007) Does Repressive Coping Promote Resilience? Affective-Autonomic Response Discrepancy during Bereavement. Journal of Personality and Social Psychology, 92, 745750. http://dx.doi.org/10.1037/0022-3514.92.4.745

[125] Wan, M.W., Abel, K.M. and Green, J. (2008) The Transmission of Risk to Children from Mothers with Schizophrenia: A Developmental Psychopathology Model. Clinical Psychology Review, 28, 613-637. http://dx.doi.org/10.1016/j.cpr.2007.09.001

[126] Foster, K., O’Brien, L. and Korhonen, T. (2012) Developing Resilient Children and Families When Parents Have Mental Illness: A Family-Focused Approach. International Journal of Mental Health Nursing, 21, 3-11. http://dx.doi.org/10.1111/j.1447-0349.2011.00754.x

[127] Kim-Cohen, J. (2007) Resilience and Developmental Psychopathology. Child and Adolescent Psychiatric Clinics of North America, 16, 271-283. http://dx.doi.org/10.1016/j.chc.2006.11.003

[128] Medalia, A. and Thysen, J. (2008) Insight into Neurocognitive Dysfunction in Schizophrenia. Schizophrenia Bulletin, 34, 1221-1230. http://dx.doi.org/10.1093/schbul/sbm144

[129] Liberzon, I. and Knox, D. (2012) Expanding Our Understanding of Neurobiological Mechanisms of Resilience by Using Animal Models. Neuropsychopharmacology, 37, 317-318. http://dx.doi.org/10.1038/npp.2011.259

[130] McCrory, E., De Brito, S.A. and Viding, E. (2010) Research Review: The Neurobiology and Genetics of Maltreatment and Adversity. Journal of Child Psychology and Psychiatry, 51, 1079-1095. http://dx.doi.org/10.1111/j.1469-7610.2010.02271.x

[131] Rutten, B.P.F., Hammels, C., Geschwind, N., Menne-Lothmann, C., Pishva, E., Schruer, K. and Wichers, M. (2013) Resilience in Mental Health: Linking Psychological and Neurobiological Perspectives. Acta Psychiatrica Scandinavica, 128, 3-20. http://dx.doi.org/10.1111/acps.12095

[132] Krishnan, V. (2014) Defeating the Fear: New Insights into the Neurobiology of Stress Susceptibility. Experimental Neurology, 261, 412-416. http://dx.doi.org/10.1016/j.expneurol.2014.05.012

[133] Eisch, A.J., Lagace, D.C., Donovan, M.H., DeCarolis, N.A., Farnbauch, L.A., Malhotra, S. and Krishnan, V. (2010) New Findings on the Neurobiology of Resilience and Susceptibility to Social Stress. European Neuropsychopharmacology, 20, S176-S190. http://dx.doi.org/10.1016/S0924-977X(10)70157-7

[134] Elisei, S., Sciarma, T., Verdolini, N. and Anastasi, S. (2013) Resilience and Depressive Disorders. Psychiatria Danubina, 25, S263-S267.

[135] Morrison, F.G. and Ressler, K.J. (2014) From the Neurobiology of Extinction to Improved Clinical Treatments. Depression and Anxiety, 31, 279-290. http://dx.doi.org/10.1002/da.22214

[136] Gillespie, C.F., Phifer, J., Bradley, B. and Ressler, K.J. (2009) Risk and Resilience: Genetic and Environmental Influences on Development of the Stress Response. Depression and Anxiety, 26, 984-992. 
http://dx.doi.org/10.1002/da.20605

[137] Fava, G.A. and Tomba, E. (2009) Increasing Psychological Well-Being and Resilience by Psychotherapeutic Methods. Journal of Personality, 77, 1903-1934. http://dx.doi.org/10.1111/j.1467-6494.2009.00604.X

[138] Panter-Brick, C. and Leckman, J.F. (2013) Resilience in Child Development: Interconnected Pathways to Wellbeing. Journal of Child Psychology and Psychiatry, 54, 333-336. http://dx.doi.org/10.1111/jcpp.12057

[139] Frangou, S. (2012) Brain Structural and Functional Correlates of Resilience in Bipolar Disorder. Frontiers in Human Neuroscience, 5, 184. http://dx.doi.org/10.3389/fnhum.2011.00184 